\title{
Simultaneous determination of uric acid and dopamine using a carbon fiber electrode modified by layer-by-layer assembly of graphene and gold nanoparticles
}

\author{
Jiao Du • Ruirui Yue $\cdot$ Fangfang Ren $\cdot$ Zhangquan Yao • \\ Fengxing Jiang • Ping Yang • Yukou Du \\ Published online: 19 May 2013 \\ (C) The Author(s) 2013. This article is published with open access at SpringerLink.com
}

\begin{abstract}
A novel layer-by-layer assembly of graphene sheets and gold nanoparticles modified carbon fiber electrode (GE/Au/GE/CFE) was successfully fabricated and applied to simultaneous determination of dopamine (DA) and uric acid (UA). The structure of $\mathrm{GE} / \mathrm{Au} / \mathrm{GE} / \mathrm{CFE}$ was characterized by scanning electron microscopy (SEM). It was observed that the gold nanoparticles were homogeneously assembled between the two layers of GE sheets. Cyclic voltammetry (CV) measurements elucidate that $\mathrm{GE} / \mathrm{Au} / \mathrm{GE} / \mathrm{CFE}$ has higher electrocatalytic activity for the oxidation of DA and UA when compared with graphene modified carbon fiber electrode (GE/CFE), and graphene and gold nanoparticles modified carbon fiber electrode (Au/GE/CFE). Simultaneous determination of UA and DA on $\mathrm{GE} / \mathrm{Au} / \mathrm{GE} / \mathrm{CFE}$ was conducted with a differential pulse voltammetry technique, and two welldefined and fully resolved anodic oxidation peaks were observed. Anodic oxidation currents of DA and UA are linear with their concentration in the range of $0.59-43.96 \mu \mathrm{M}$ and 12.6-413.62 $\mu \mathrm{M}$, respectively. Moreover, the composite electrode displays high reproducibility and selectivity for the determination of UA and DA.
\end{abstract}

Keywords Gold nanoparticles · Graphene · Dopamine · Uric acid

\section{Introduction}

Dopamine (DA), one of the most important catecholamine neurotransmitters, exists in the mammalian central nervous system at very low concentrations and plays a significant

J. Du $\cdot$ R. Yue $\cdot$ F. Ren $\cdot$ Z. Yao $\cdot$ F. Jiang $\cdot$ P. Yang $\cdot$ Y. Du $(\bowtie)$

College of Chemistry, Chemical Engineering and Materials

Science, Soochow University, Suzhou 215123,

People's Republic of China

e-mail: duyk@suda.edu.cn role in central nervous, endocrine, and cognitive functions. Brain tissues will be severely impacted when the level of DA fluctuates. Deficiency of DA may result in serious neurological disorders, such as Parkinson's disease and addiction [1-4]. Uric acid (UA), the primary end product of purine metabolism, is present in biological fluids such as blood or urine. Abnormal levels of UA are symptoms of several diseases such as gout and hyperuricemia $[5,6]$. Therefore, it is important to determine these species. Since DA and UA are electroactive materials, electrochemical methods appear to be suitable for their quantitative determination. Moreover, electrochemical methods are highly sensitive, easily operable, and cost effective [7-11]. However, a major problem that inhibits electrochemical determination is that UA and DA have similar oxidation potential at most of the conventional solid electrodes. In the actual samples, UA presents in concentrations much higher than DA [12, 13]. Therefore, it is critically important to prepare a sensitive and accurate electrode for simultaneous determination of $\mathrm{UA}$ and DA.

Graphene-metal nanoparticles composite has attracted extensive attention in recent years in many fields such as sensor and fuel cells [14, 15]. Gold nanoparticles, which are usually applied to bimolecular immobilization, have many advantages such as excellent catalytic activity, huge surface area, effective mass transport, and hospitable environment. Furthermore, they can serve on electron tunnel to promote electron exchange at electron/protein interface [16, 17], and thereby gold nanoparticles have found many applications in biosensors $[18,19]$. Graphene (GE), a one-atom-thick $\mathrm{sp}^{2}$ bonded carbon sheet, has attracted tremendous attention in recent years due to its large amount of edge-plan-like defects and large specific surface area [20-22]. The elusive two-dimensional structure of GE contributes to 
numerous unique electronic properties, such as the quantum Hall effect and transport via relativistic Dirac fermions [23, 24], making GE possess high electron conductivity and good biocompatibility. The combination of GE and gold nanoparticles can increase electrode surface and enhance optical, electronic, and catalytic properties. Moreover, GE and gold nanoparticles offer synergistic effects in their composite electrocatalytic applications [14, 24]. Li et al. [25] developed GE and gold nanoparticles modified electrodes which can selectively determine DA with a high detection limit $(1.86 \mu \mathrm{M})$. To the best of our knowledge, there have been no reports about the fabrication and application of GE and gold nanoparticles layer-by-layer modified electrode for simultaneous detection of DA and UA.

In this work, GE and gold nanoparticles were assembled into a layer-by-layer structure on the carbon fiber electrode, which was endowed with large surface area and high electron transfer ability. The graphene sheets and gold nanoparticles modified carbon fiber electrode (GE/Au/GE/CFE) was used to simultaneously determine UA and DA. For comparison, the electrocatalytic performance of graphene modified carbon fiber electrode (GE/CFE), and graphene and gold nanoparticles modified carbon fiber electrode (Au/GE/CFE) towards UA and DA oxidation was also studied.

\section{Experimental}

\section{Reagents and materials}

Graphite powder, disodium hydrogen phosphate, and sodium dihydrogen phosphate were obtained from Sinopharm Chemicals Reagent Co., Ltd. (China). Uric acid and dopamine were purchased from Acros Organics and used as received. All chemicals were of analytical reagent grade. All solution was prepared with secondary distilled water. Graphene oxide (GO) nanosheets were prepared according to the literature $[15,26]$.
Apparatus

The morphology of obtained electrodes was characterized by emission scanning electron microscopy (SEM) (S-4700; Hitachi High Technologies Corporation, Japan). A CHI650D electrochemical workstation (Shanghai Chenhua Instrument Plant, China) was used to take the electrochemical experiments. A standard three-electrode configuration, consisting of obtained sample electrodes as the working electrodes, a platinum wire with a diameter of $0.5 \mathrm{~mm}$ as the counter electrode, and a saturated calomel electrode (SCE) as the reference electrode, was used throughout the experiment. Also, $0.1 \mathrm{M}$ phosphate buffer solution (PBS) $(\mathrm{pH}=7.0)$ was used as an electrolyte solution. All experiments were carried out at room temperature.

\section{Electrode preparation}

The preparation of $0.5 \mathrm{mg} / \mathrm{mL} \mathrm{GO}$ nanosheets solution was as follows: $10 \mathrm{mg}$ obtained $\mathrm{GO}$ was dispersed into $10 \mathrm{~mL}$ of secondly distilled water under ultrasonic bath for $90 \mathrm{~min}$. Impurities were centrifuged from this suspension. The obtained GO ink $(0.15 \mathrm{~mL})$ was dropcast onto CFE and then dried in air. The GO on CFE was reduced at a constant potential of $-0.9 \mathrm{~V}$ in Na-PBS $(0.1 \mathrm{M}, \mathrm{pH}=4.1)$ solution, and then gold nanoparticles were deposited thereon by reduction of $0.3 \mathrm{mM} \mathrm{HAuCl}{ }_{4}$ solution at a constant potential of $-0.2 \mathrm{~V}$ with a certain electric quantity of $6.0 \times 10^{3} \mathrm{C}$ calculated as $4.08 \mu \mathrm{g}$. Subsequently, the GO ink $(0.15 \mathrm{~mL})$ was again dropcast onto the above obtained electrode and dried in air, and then reduced at a constant potential of $-0.9 \mathrm{~V}$ in Na-PBS $(0.1 \mathrm{M}, \mathrm{pH}=4.1)$ solution to obtain a GE/Au/GE/CFE composite electrode (shown in Scheme 1). Preparation of GE/CFE or Au/GE/CFE was similar to $\mathrm{GE} / \mathrm{Au} / \mathrm{GE} / \mathrm{CFE}$ just using $\mathrm{GE}$ or $\mathrm{Au}$ and $\mathrm{GE}$ as the precursor instead of GE, $\mathrm{Au}$, and GE. The electrode area immersed into the solution is $1 \mathrm{~cm} \times 360 \mu \mathrm{m}$.
Scheme 1 Illustration of the fabrication of $\mathrm{GE} / \mathrm{Au} / \mathrm{GE} / \mathrm{CFE}$
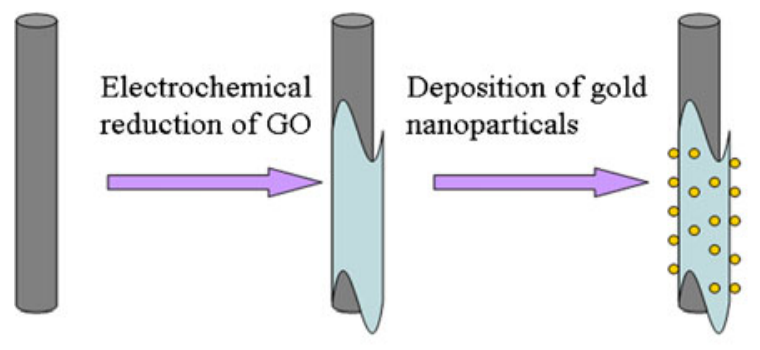

Electrochemical reduction of $\mathrm{GO}$

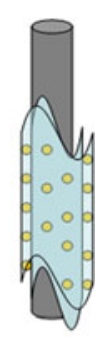

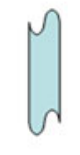
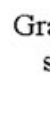

Gold nanoparticle 


\section{Results and discussion}

Characterization of obtained electrodes

The morphology of the obtained electrodes was examined by SEM. Figure 1a shows the surface morphology of GE/CFE. It
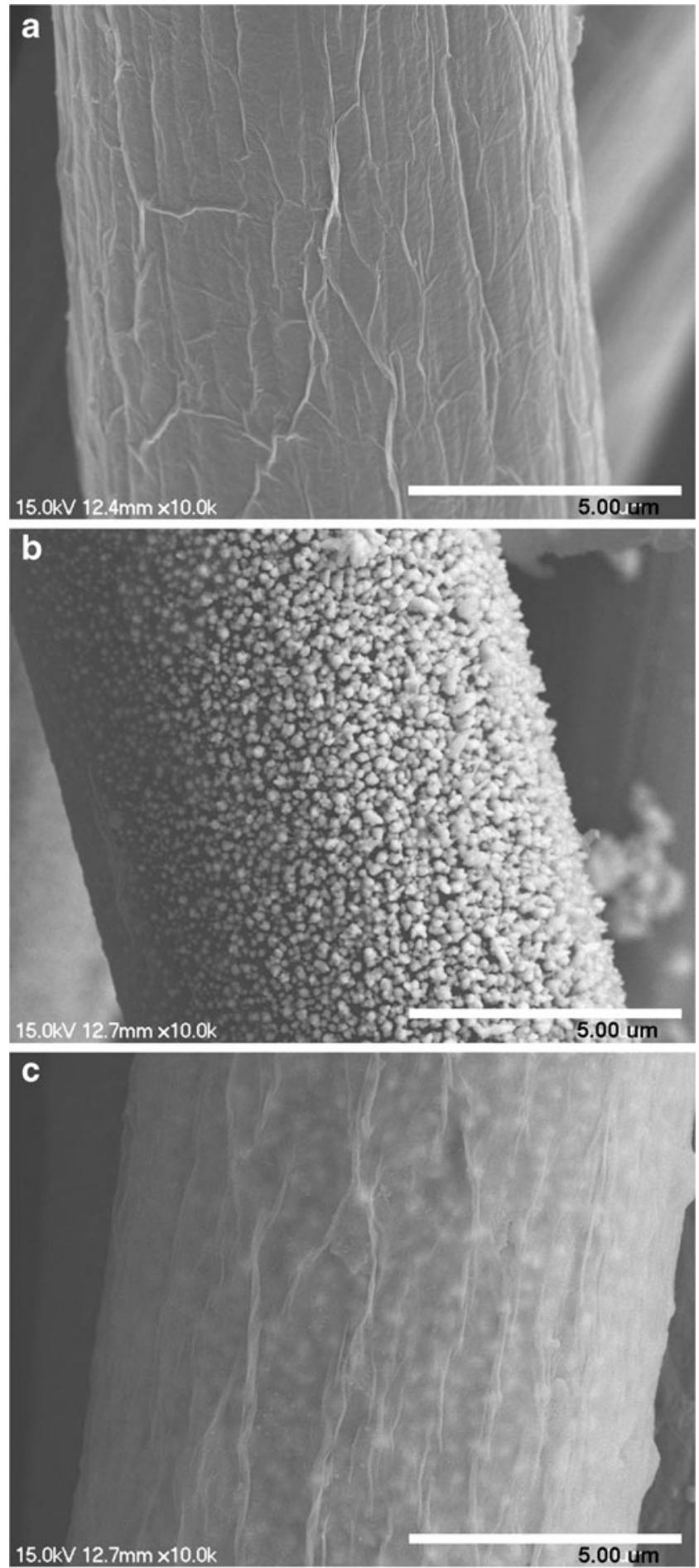

Fig. 1 SEM images of a GE/CFE, b $\mathrm{Au} / \mathrm{GE} / \mathrm{CFE}$, and $\mathbf{c} \mathrm{GE} / \mathrm{Au} / \mathrm{GE} /$ CFE electrodes can be seen that GE uniformly wraps on the surface of CFE. Many wrinkles are observed on the surface of the electrode, indicating the increase in superficial area of the GE/CFE electrode. Figure $1 \mathrm{~b}$ is the image of $\mathrm{Au} / \mathrm{GE} / \mathrm{CFE}$. The image shows that gold nanoparticles are well distributed to form a nanocomposite on the surface of GE sheets. The sizes of $\mathrm{Au}$ nanoparticles are homogeneous, and the distribution of nanoparticles is very uniform and dense. The SEM image of $\mathrm{GE} / \mathrm{Au} / \mathrm{GE} / \mathrm{CFE}$ is shown in Fig. 1c. It can be seen that GE layer likes filmy gauze wholly coated on the surface of gold nanoparticles, and wholly wraps gold nanoparticles. There are no aggregation of GE sheets and free gold nanoparticles. Furthermore, an increase in the surface roughness is observed, which gives rise to much higher active surface area for $\mathrm{Au} / \mathrm{CFE}$, and thus enhances its electrochemical activity.

Figure 2 shows the $\mathrm{CV}$ responses of the three electrodes in $10 \mathrm{mM} \mathrm{Fe}(\mathrm{CN})_{6}^{3 / 4}+0.1 \mathrm{M} \mathrm{KCl}$ solution. A pair of poor redox peaks is observed in the $\mathrm{CV}$ response of GE/CFE, indicating a poor electron transfer at the interface of $\mathrm{GE} / \mathrm{CFE}$. Compared with the $\mathrm{CV}$ response of GE/CFE, an obvious increase in the redox peak current and a narrow peak potential difference are observed in the $\mathrm{CV}$ response of $\mathrm{Au} / \mathrm{GE} / \mathrm{CFE}$, suggesting that the introduction of gold nanoparticles can enhance the electrochemical activity of obtained electrode. This may contribute to the huge surface area of gold nanoparticles. A pair of well-defined redox peaks with the smallest peak potential separation of about $100 \mathrm{mV}$ can be observed in the $\mathrm{CV}$ response of $\mathrm{GE} / \mathrm{Au} / \mathrm{GE} / \mathrm{CFE}$. The enhanced peak current intensity and the smallest peak potential separation may be due to the high electric transfer kinetics and the huge surface of $\mathrm{GE} / \mathrm{Au} / \mathrm{GE} / \mathrm{CFE}[1]$.

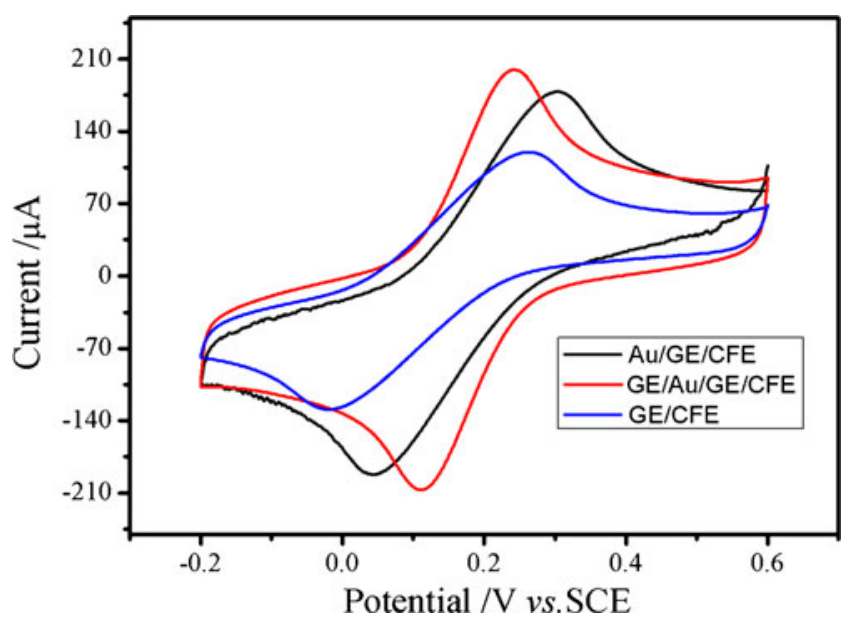

Fig. $2 \mathrm{CVs}$ of $\mathrm{Au} / \mathrm{GE} / \mathrm{CFE}, \mathrm{GE} / \mathrm{CFE}$, and $\mathrm{GE} / \mathrm{Au} / \mathrm{GE} / \mathrm{CFE}$ electrodes recorded in $10 \mathrm{mM} \mathrm{Fe}(\mathrm{CN})_{6}^{3-/ 4-}+0.1 \mathrm{M} \mathrm{KCl}$ solution at scan rate of $50 \mathrm{mV} / \mathrm{s}$ 
Cyclic voltammetric detection of UA and DA

Figure $3 \mathrm{a}$ and $\mathrm{b}$ shows the $\mathrm{CV}$ responses of $\mathrm{DA}$ and UA on $\mathrm{GE} / \mathrm{CFE}, \mathrm{Au} / \mathrm{GE} / \mathrm{CFE}$, and $\mathrm{GE} / \mathrm{Au} / \mathrm{GE} / \mathrm{CFE}$, respectively. In Fig. 3a, for $0.5 \mathrm{mM} \mathrm{DA}$ solution, the anodic oxidation peak currents are $80 \mu \mathrm{A}, 110 \mu \mathrm{A}$, and $150 \mu \mathrm{A}$ for GE/CFE, $\mathrm{Au} / \mathrm{GE} / \mathrm{CFE}$, and $\mathrm{GE} / \mathrm{Au} / \mathrm{GE} / \mathrm{CFE}$, respectively. In Fig. 3b, for $1.0 \mathrm{mM} \mathrm{UA}$ solution the anodic peak current at GE/CFE is $150 \mu \mathrm{A}$, which becomes as low as $25 \mu \mathrm{A}$ with the $\mathrm{Au} / \mathrm{GE} / \mathrm{CFE}$ and $50 \mu \mathrm{A}$ with the GE/Au/GE/CFE. The anodic peak potential of UA at GE/CFE is more positive compared with that of the other two electrodes. Different electrodes are used to simultaneously determine UA and DA in $0.1 \mathrm{M}$ PBS $(\mathrm{pH}=7.0)$ solution containing $0.25 \mathrm{mM} \mathrm{UA}$ and $0.25 \mathrm{mM}$ DA by CV. Figure $3 \mathrm{c}$ shows the electrocatalytic oxidation $\mathrm{CV}$ responses of $\mathrm{UA}$ and $\mathrm{DA}$ in the mixture solution on GE/CFE, Au/GE/CFE, and GE/Au/GE/CFE electrodes. As can be seen, two well-defined peaks at $0.3 \mathrm{~V}$ and $0.15 \mathrm{~V}$ are observed for all the $\mathrm{CV}$ responses of different electrodes. Towards UA and DA electrooxidation, the $\mathrm{GE} / \mathrm{Au} / \mathrm{GE} / \mathrm{CFE}$ shows the highest oxidation currents of $100 \mu \mathrm{A}$ and $80 \mu \mathrm{A}$, while the oxidation currents are $70 \mu \mathrm{A}$ and $50 \mu \mathrm{A}$, and $50 \mu \mathrm{A}$ and $40 \mu \mathrm{A}$ for $\mathrm{Au} / \mathrm{GE} / \mathrm{CFE}$ and

\section{a}

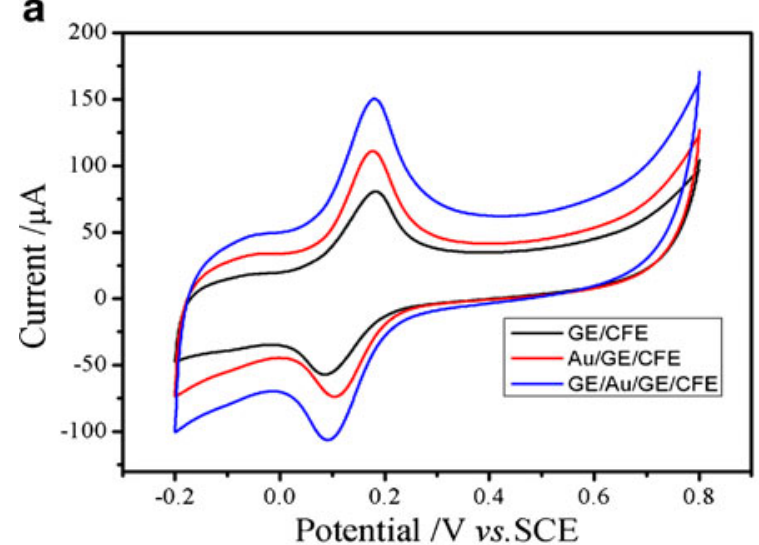

C

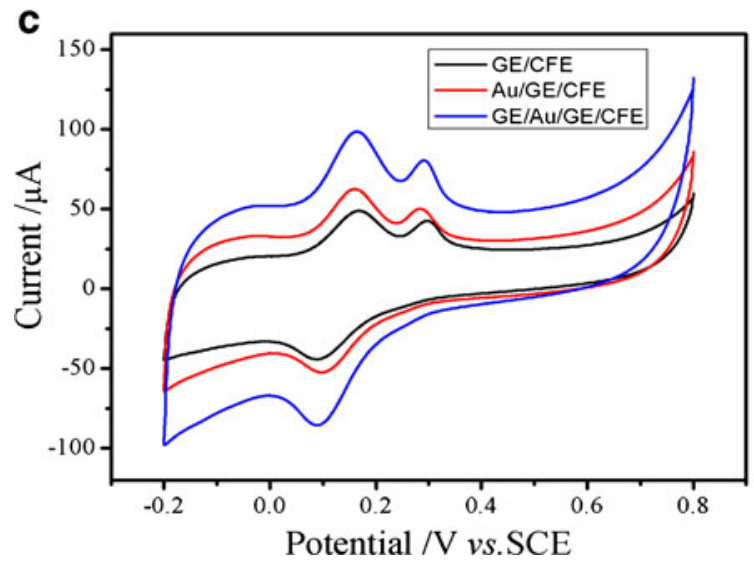

GE/CFE, respectively. The above result indicates that $\mathrm{GE} / \mathrm{Au} / \mathrm{GE} / \mathrm{CFE}$ shows higher electrocatalysis response to the oxidation of UA and DA. The reason may be that the higher specific surface area and the larger amount of edgeplan-like defects of $\mathrm{GE} / \mathrm{Au} / \mathrm{GE} / \mathrm{CFE}$ can provide more active sites for the oxidation of UA and DA as compared with other electrodes and be conducive to the separation of DA and UA. Additionally, GE is a highly conductive material, and gold nanoparticles can promote electron exchange. The composited GE and gold nanoparticles offer synergistic effects in electric catalytic applications.

Effects of scan rate on the oxidation of UA and DA

The effects of scan rate $(v)$ on the electrocatalytic activity of $\mathrm{GE} / \mathrm{Au} / \mathrm{GE} / \mathrm{CFE}$ towards oxidation of UA and DA have been investigated by $\mathrm{CV}$ (Fig. 4a, b). It can be seen that both the peak potentials $\left(E_{\mathrm{pa}}\right)$ and peak currents $\left(I_{\mathrm{pa}}\right)$ are dependent on the scan rate. When the scan rate increases, small positive shifts in the UA and DA oxidation peaks are observed, suggesting that the adsorption of UA and DA does not occur on GE/Au/GE/CFE in $0.1 \mathrm{M}$ PBS $(\mathrm{pH}=$ 7.0) solution. For both UA and DA, the redox peak currents

\section{b}

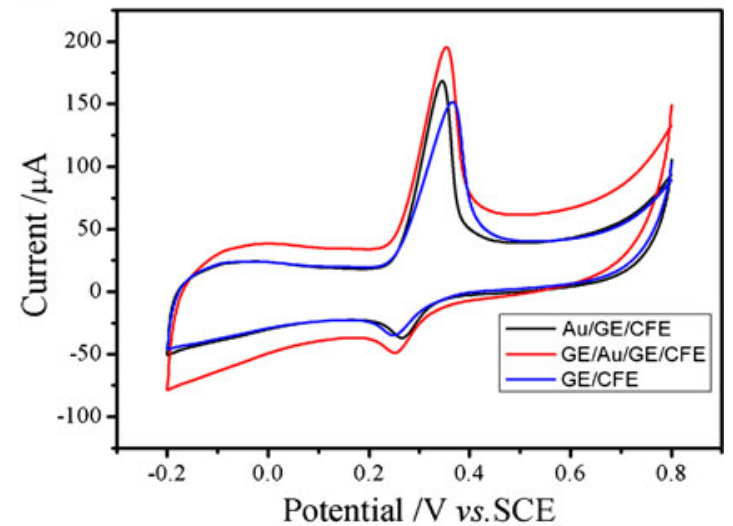

Fig. $3 \mathrm{CV}$ responses of GE/CFE, $\mathrm{Au} / \mathrm{GE} / \mathrm{CFE}$, and $\mathrm{GE} / \mathrm{Au} / \mathrm{GE} / \mathrm{CFE}$ in $0.1 \mathrm{M} \mathrm{PBS}(\mathrm{pH}=7.0)$ containing a $0.5 \mathrm{mM} \mathrm{DA}, \mathbf{b} 1.0 \mathrm{mM} \mathrm{UA}$, and c $0.25 \mathrm{mM}$ UA and $0.25 \mathrm{mM}$ DA. Scan rate: $50 \mathrm{mV} / \mathrm{s}$ 
a

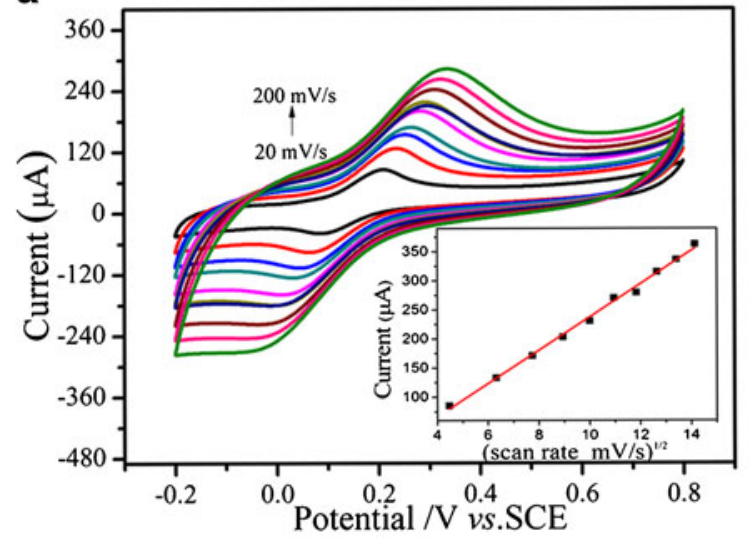

b

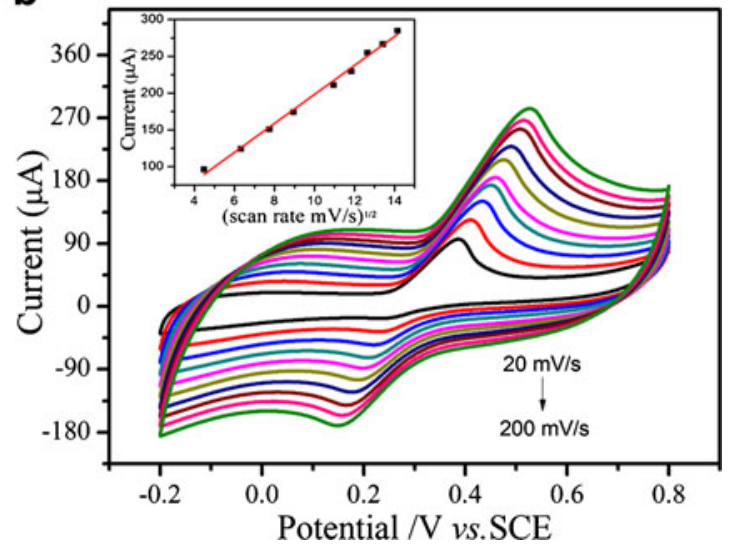

Fig. $4 \mathrm{CV}$ curves of $\mathrm{GE} / \mathrm{Au} / \mathrm{GE} / \mathrm{CFE}$ in $0.1 \mathrm{M}$ PBS $(\mathrm{pH}=7.0)$ solution containing $0.25 \mathrm{mM}$ DA (a) and $0.5 \mathrm{mM}$ UA (b) at different scan rates of $20,40,60,80,100,120,140,160,180$, and $200 \mathrm{mV} / \mathrm{s}$. Inset: plot of peak current versus the square root of scan rate

gradually increase as the scan rate increases, and a linear relation between the anodic currents and the square root of scan rates at the range of $20-200 \mathrm{mV} / \mathrm{s}$ can be observed. The linear equations are expressed as follows:

$$
\begin{aligned}
I_{\mathrm{pa}}(\mu \mathrm{A}) & =28.53 v^{1 / 2}(\mathrm{mV} / \mathrm{s})-47.82(\mathrm{DA}) ; I_{\mathrm{pa}}(\mu \mathrm{A}) \\
& =19.70 v^{1 / 2}(\mathrm{mV} / \mathrm{s})+1.205(\mathrm{UA}),
\end{aligned}
$$

with linear relative coefficients both of 0.995 . The above results indicate that the oxidation of UA and DA on $\mathrm{GE} / \mathrm{Au} / \mathrm{GE} / \mathrm{CFE}$ is a diffusion-controlled process. In addition, the electrode reactions of DA and UA are quasireversible as the redox peaks potentials vary with the scan rates [13].

Effects of $\mathrm{pH}$ on the oxidation of UA and DA

The effects of solution $\mathrm{pH}$ on the peak currents and peak potentials of UA and DA oxidation are studied by differential pulse voltammetry (DPV). The results are shown in Fig. 5a and b. As shown in Fig. 5a, the oxidation potentials shift negatively with the increase in the

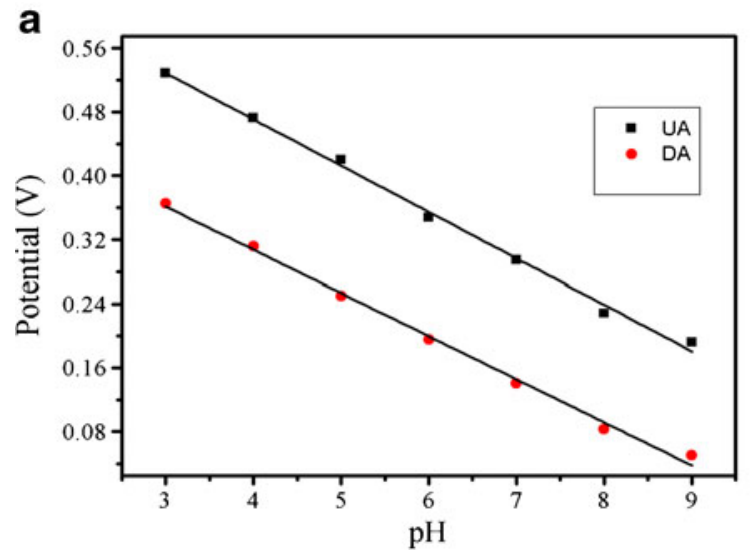

solution $\mathrm{pH}$, and the slopes of -54 and $-58 \mathrm{mV} / \mathrm{pH}$ for DA and UA in the $\mathrm{pH}$ range of 3.0-9.0 are obtained. These slopes are close to a Nernst system, defined as $-59 \mathrm{mV} / \mathrm{pH}$ at $25^{\circ} \mathrm{C}$, implying that the total number of electrons and protons taking part in the charge transfer is the same, that is, for the oxidation of DA and UA two electrons and two protons are involved, shown as follows [20]:<smiles>C#CC(=O)C1C=C(CCN)C=CC1=O</smiles>

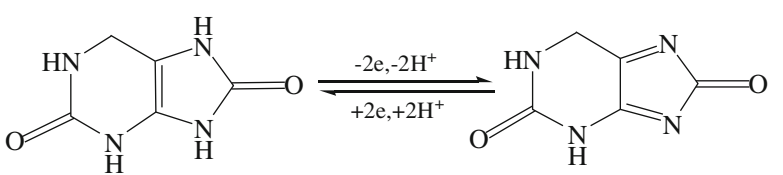

UA

The oxidation peak current of UA increases as the $\mathrm{pH}$ value increases up to 6.0 and then decreases quickly with continue increasing of $\mathrm{pH}$. By comparison, the oxidation peak current of DA decreases as the $\mathrm{pH}$ is increased. The $\mathrm{pH}$

b

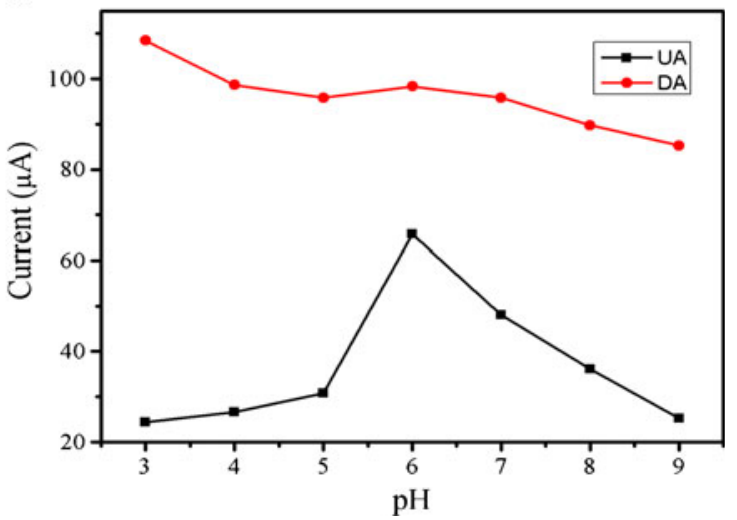

Fig. 5 Dependence of the a anodic peak potentials and $\mathbf{b}$ anodic currents as a function of the solution pH for $0.5 \mathrm{mM}$ DA and $0.8 \mathrm{mM}$ UA 

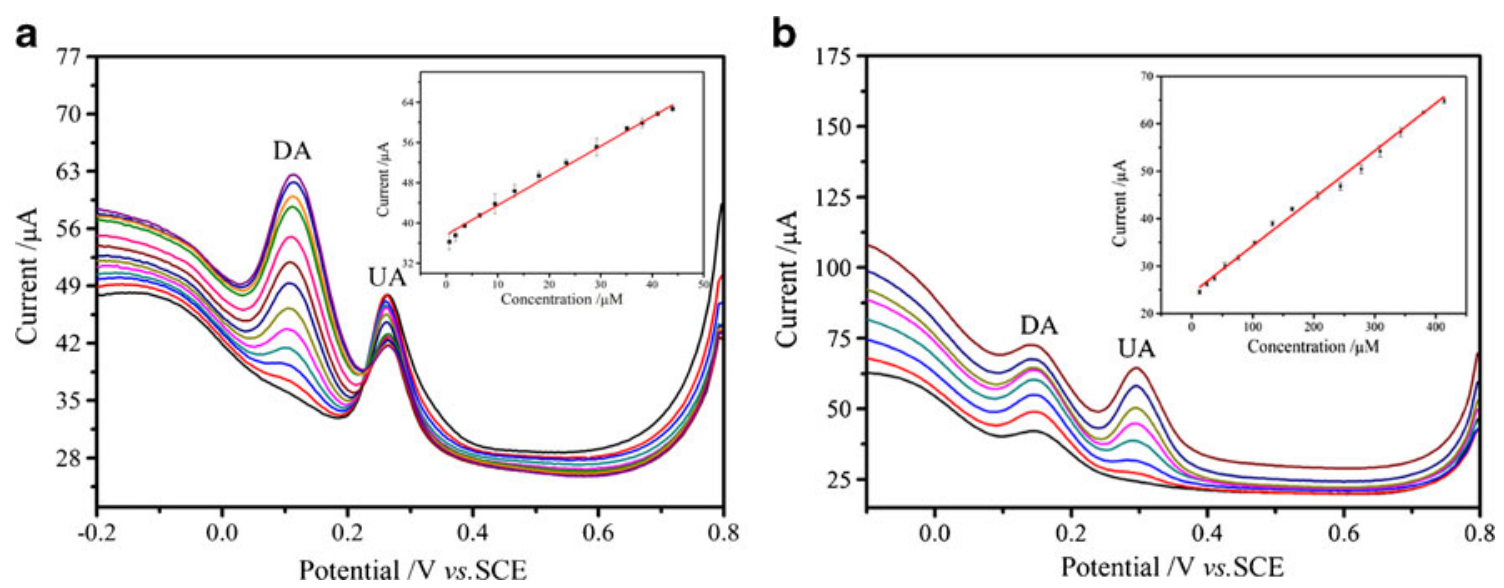

Fig. 6 DPV curves of a $0.15 \mathrm{mM}$ UA with different concentrations of DA and b $8 \mu \mathrm{M}$ DA with different concentrations of UA. Insets: plots of oxidation currents versus the concentration of DA and UA, respectively

value of human blood and urine is close to 7.0 , thus $0.1 \mathrm{M}$ PBS solution with $\mathrm{pH}=7.0$ is chosen for simultaneous determination of UA and DA.

Simultaneous determination of UA and DA

As shown by the above results, the difference in the oxidation peak potentials for DA and UA is large enough for separation and simultaneous determination of DA and UA in a mixture. DPV has been used to simultaneously determine UA and DA at $\mathrm{GE} / \mathrm{Au} / \mathrm{GE} / \mathrm{CFE}$. The electrooxidation processes of DA and UA in the mixture are evaluated when the concentration of one species changes and the other one keeps constant. Figure 6a depicts the DPV curves of various DA concentrations at $\mathrm{GE} / \mathrm{Au} / \mathrm{GE} / \mathrm{CFE}$ in presence of $0.15 \mathrm{mM}$ UA. As shown in Fig. 6a, the oxidation currents of UA show small change when DA concentration increases; it indicates that the addition of DA does not affect the determination of UA. The inset in Fig. 6a depicts the linear relationship between the oxidation peak currents and DA concentration in the range of 0.59-43.955 $\mu \mathrm{M}$. The corresponding linear regression equation is defined as $I_{\mathrm{pa}}=$ $37.4099+0.5996 C_{\mathrm{DA}}(R=0.992)$, and the lower detection limit for DA is observed to be $0.59 \mu \mathrm{M}(\mathrm{S} / \mathrm{N}=3)$, which is lower than previously reported results [27-29]. Meanwhile, a similar experiment was conducted with UA in the presence of $8 \mu \mathrm{M} \mathrm{DA}$. In Fig. 6b, although the oxidation currents of DA change when UA concentration increases, the determination of UA is not affected. As shown in the inset of Fig. $6 \mathrm{~b}$, the linear relationship between the oxidation peak currents of UA and the UA concentration is defined as $I_{\mathrm{pa}}=24.262+0.1001 C_{\mathrm{UA}}(R=0.997)$ in the range of $12.6-413.62 \mu \mathrm{M}$ and the lower detection limit is observed to be $12.6 \mu \mathrm{M}(\mathrm{S} / \mathrm{N}=3)$, which is lower than what was previously reported $[28,29]$. The above results show that $\mathrm{GE} / \mathrm{Au} / \mathrm{GE} / \mathrm{CFE}$ is well response for the determination of DA and UA.
Reproducibility and interference of GE/Au/GE/CFE

In the reproducibility tests, $\mathrm{GE} / \mathrm{Au} / \mathrm{GE} / \mathrm{CFE}$ was used to repeatedly $(n=6)$ determine $0.14 \mathrm{mM}$ DA and $0.42 \mathrm{mM}$ $\mathrm{UA}$ in the mixture solution. It is found that the relative standard deviations (RSD) for DA and UA are $1.25 \%$ and $2.36 \%$ indicating the excellent reproducibility of the prepared composite electrode. The measured currents of the electrode maintain at $96.6 \%$ for DA and $96.1 \%$ for UA after 7 days. The test about the influence of various interferents that may exist in the real samples on the determination of DA and UA was also carried out. When 10times concentration of $\mathrm{NaCl}, \mathrm{KCl}, \mathrm{NaNO}_{3}$, ascorbic acid, glucose, urea, and $\mathrm{NH}_{4} \mathrm{Cl}$ were added into the mixture of $0.25 \mathrm{mM}$ UA and $0.25 \mathrm{mM} \mathrm{DA}$, no obvious interference was observed (shown in Table 1), demonstrating the good anti-interference ability of as-fabricated $\mathrm{GE} / \mathrm{Au} / \mathrm{GE} / \mathrm{CFE}$ composite electrode. It is worth to mention that the interference for DA is lower than that of UA, which may be attributed to the $\pi-\pi$ interaction between the phenyl structure of DA molecule and the two-dimensional hexagonal carbon structure of GE [30].

Table 1 Results of interference study on the response of UA and DA

\begin{tabular}{lll}
\hline $\begin{array}{l}\text { Interfering } \\
\text { substances }\end{array}$ & $\begin{array}{l}\text { Peak current intensity } \\
\text { variation (DA) }\end{array}$ & $\begin{array}{l}\text { Peak current intensity } \\
\text { variation (UA) }\end{array}$ \\
\hline $\mathrm{NaCl}$ & $0.67 \%$ & $2.10 \%$ \\
$\mathrm{KCl}$ & $2.18 \%$ & $1.66 \%$ \\
$\mathrm{Ascorbic}$ acid & $2.30 \%$ & $-1.80 \%$ \\
$\mathrm{NaNO}_{3}$ & $3.40 \%$ & $3.90 \%$ \\
$\mathrm{NH}_{4} \mathrm{Cl}$ & $-0.70 \%$ & $-5.06 \%$ \\
$\mathrm{Glucose}_{\text {Urea }}^{-1.75 \%}$ & $-3.69 \%$ \\
\hline
\end{tabular}




\section{Conclusion}

In summary, a novel electrode based on layer-by-layer assembly of GE sheets and gold nanoparticles has been developed by simple electrochemical reduction of GO and potentiostatic electrodeposition of gold nanoparticles onto GE sheets. The prepared GE/Au/GE/CFE composite electrode was used to simultaneously determine UA and DA. It is found that two clear and well-separated oxidation peaks are observed in the determination of UA and DA at $\mathrm{GE} / \mathrm{Au} / \mathrm{GE} / \mathrm{CFE}$ as compared with the other two electrodes. The introduction of GE and gold nanoparticles and the structure of GE/Au/GE/CFE increase the effective electroactive surface area, and also enhance the ability of electron transfer. Additionally, the low detection limit and wide detection range evince that the developed electrode is of high selectivity and good reproducibility towards UA and DA determination. Moreover, the fabrication of the developed electrode is low cost and easy workable.

Acknowledgments The authors appreciate the supports of the National Natural Science Foundation of China (grant nos. 20933007 and 51073114), the Priority Academic Program Development of Jiangsu Higher Education Institutions (PAPD), and the Academic Award for Young Graduate Scholar of Soochow University.

Open Access This article is distributed under the terms of the Creative Commons Attribution License which permits any use, distribution, and reproduction in any medium, provided the original author(s) and the source are credited.

\section{References}

1. Ping J, Wu J, Wang Y, Ying Y (2012) Simultaneous determination of ascorbic acid, dopamine and uric acid using high-performance screen-printed graphene electrode. Biosens Bioelectron 34:70-76

2. Ciszewski A, Milczarek G (1999) Polyeugenol-modified platinum electrode for selective detection of dopamine in the presence of ascorbic acid. Anal Chem 71:1055-1061

3. Salimi A, Abdi K, Khayatian GR (2004) Amperometric detection of dopamine in the presence of ascorbic acid using a nafion coated glassy carbon electrode modified with catechin hydrate as a natural antioxidant. Microchim Acta 144:161-169

4. Zhao Y, Gao Y, Zhan D, Liu H, Zhao Q, Kou Y, Shao Y, Li M, Zhuang Q, Zhu Z (2005) Selective detection of dopamine in the presence of ascorbic acid and uric acid by a carbon nanotubesionic liquid gel modified electrode. Talanta 66:51-57

5. Ensafi AA, Taei M, Khayamian T, Arabzadeh A (2010) Highly selective determination of ascorbic acid, dopamine, and uric acid by differential pulse voltammetry using poly(sulfonazo III) modified glassy carbon electrode. Sensors Actuators B 147:213-221

6. Mallesha M, Manjunatha R, Nethravathi C, Suresh GS, Rajamathi M, Melo JS, Venkatesha TV (2011) Functionalized-graphene modified graphite electrode for the selective determination of dopamine in presence of uric acid and ascorbic acid. Bioelectrochemistry $81: 104-108$

7. Wu J, Suls J, Sansen W (2000) Amperometric determination of ascorbic acid on screen-printing ruthenium dioxide electrode. Electrochem Commun 2:90-93
8. Gea S, Yan M, Lua J, Zhang M, Yu F, Yu J, Song X, Yu S (2012) Electrochemical biosensor based on graphene oxide-Au nanoclusters composites for L-cysteine analysis. Biosens Bioelectron 31:49-54

9. Jiang F, Yue R, Du Y, Xu J, Yang P (2013) A one-pot 'green' synthesis of Pd-decorated PEDOT nanospheres for nonenzymatic hydrogen peroxide sensing. Biosens Bioelectron 44:127-131

10. Wu L, Feng L, Ren J, Qu X (2012) Electrochemical detection of dopamine using porphyrin-functionalized graphene. Biosens Bioelectron 34:57-62

11. Wang L, Qin X, Liu S, Luo Y, Asiri A, Al-Youbi A, Sun X (2012) Single-stranded DNA-mediated immobilization of graphene on a gold electrode for sensitive and selective determination of dopamine. ChemPlusChem 77:19-22

12. Mahshid S, Li C, Mahshid SS, Askari M, Dolati A, Yang L, Luo S, Cai Q (2011) Sensitive determination of dopamine in the presence of uric acid and ascorbic acid using $\mathrm{TiO}_{2}$ nanotubes modified with $\mathrm{Pd}, \mathrm{Pt}$ and $\mathrm{Au}$ nanoparticles. Analyst 136:2322-2329

13. Hou S, Kasner ML, Su S, Patel K, Cuellari R (2010) Highly sensitive and selective dopamine biosensor fabricated with silanized graphene. J Phys Chem C 114:14915-14921

14. Guo S, Wen D, Zhai Y, Dong S, Wang E (2010) Platinum nanoparticle ensemble-on-graphene hybrid nanosheet: one-pot, rapid synthesis, and used as new electrode material for electrochemical sensing. ACS Nano 7:3959-3968

15. Yao Z, Zhu M, Jiang F, Du Y, Wang C, Yang P (2012) Highly efficient electrocatalytic performance based on Pt nanoflowers modified reduced graphene oxide/carbon cloth electrode. J Mater Chem 22:13707-13713

16. Li J, Fan C, Xiao F, Yan R, Fan S, Zhao F, Zeng B (2007) Influence of ionic liquids on the direct electrochemistry of glucose oxidase entrapped in nanogold- $N, N$-dimethylformamide-ionic liquid composite film. Electrochim Acta 52:6178-6185

17. Lu J, Liu S, Ge S, Yan M, Yu J, Hu X (2012) Ultrasensitive electrochemical immunosensor based on Au nanoparticles dotted carbon nanotube-graphene composite and functionalized mesoporous materials. Biosens Bioelectron 33:29-35

18. Cui F, Zhang X (2012) Electrochemical sensor for epinephrine based on a glassy carbon electrode modified with graphene/gold nanocomposites. J Electroanal Chem 669:35-41

19. Shanmugasundaram K, Subramanian P, Paramasivam M, Iyengar GA, Lee KP (2011) Preparation of a functional nanofibrous polymer membrane incorporated with poly(2-aminothio phenol) stabilized gold nanoparticles. Gold Bull 44:37-42

20. Yue Y, Hu G, Zheng M, Guo Y, Cao J, Shao S (2012) A mesoporous carbon nanofiber-modified pyrolytic graphite electrode used for the simultaneous determination of dopamine, uric acid, and ascorbic acid. Carbon 50:107-114

21. Kim YR, Bong S, Kang YJ, Yang Y, Mahajan RK, Kim JS, Kim H (2010) Electrochemical detection of dopamine in the presence of ascorbic acid using graphene modified electrodes. Biosens Bioelectron 25:2366-2369

22. Luo J, Jiang S, Zhang H, Jiang J, Liu X (2012) A novel nonenzymatic glucose sensor based on $\mathrm{Cu}$ nanoparticle modified graphene sheets electrode. Anal Chim Acta 709:47-53

23. Wang Y, Li Y, Tang L, Lu J, Li J (2009) Application of graphenemodified electrode for selective detection of dopamine. Electrochem Commun 11:889-892

24. Zhou K, Zhu Y, Yang X, Li C (2010) Electrocatalytic oxidation of glucose by the glucose oxidase immobilized in graphene-Aunafion biocomposite. Electroanalysis 22:259-264

25. Li J, Yang J, Yang Z, Li Y, Yu S, Xu Q, Hu X (2012) Graphene-Au nanoparticles nanocomposite film for selective electrochemical determination of dopamine. Anal Methods 4:1725-1728

26. Hummers WS, Offeman RE (1958) Preparation of graphitic oxide. J Am Chem Soc 80:1339-1339 
27. Lin $\mathrm{K}$, Tsai T, Chen $\mathrm{S}$ (2010) Performing enzyme-free $\mathrm{H}_{2} \mathrm{O}_{2}$ biosensor and simultaneous determination for AA, DA and UA by MWCNT-PEDOT film. Biosens Bioelectron 26:608614

28. Thiagarajan S, Chen S (2007) Preparation and characterization of PtAu hybrid film modified electrodes and their use in simultaneous determination of dopamine, ascorbic acid and uric acid. Talanta $74: 212-222$
29. Brownson D, Foster C, Banks C (2012) The electrochemical performance of graphene modified electrodes: an analytical perspective. Analyst 137:1815-1823

30. Pruneanu S, Pogacean F, Biris AR, Ardelean S, Canpean V, Blanita G, Dervishi E, Biris AS (2011) Novel graphene-gold nanoparticle modified electrodes for the high sensitivity electrochemical spectroscopy detection and analysis of carbamazepine. J Phys Chem C 115:23387-23394 